\title{
Resale of recalled children's products online: an examination of the world's largest yard sale
}

\author{
Keri Brown Kirschman, Gary A Smith
}

Injury Prevention 2007;13:228-231. doi: 10.1136/ip.2006.013102

See end of article for authors' affiliations

\section{Correspondence to:} Dr K J Brown Kirschman, Department of Psychology, 300 College Way, University of Dayton, Dayton, $\mathrm{OH}$ 45409, USA; KirschKe@ notes.udayłon.edu

Accepted 8 May 2007

\begin{abstract}
Objective: To examine an online auction site for the presence and sale of children's products and toys previously recalled because of safety concerns.

Methods: Targeted items were randomly selected from US Consumer Product Safety Commission (CPSC) press releases of recalled children's products dated 1992-2004. Auction listings from eBay were searched for the 150 targeted recalled items for 30 days. Item, seller, and buyer information were recorded from the auction listings.

Results: 190 auctions contained or were suspected to contain a recalled children's item from the target list. Most of the recalled items were listed for sale from addresses within the United States, with sellers from Canada, Australia, Great Britain, and Ireland also represented. On average, six bids were placed on each recalled item, with $70 \%$ of auctions eventuating in a sale.

Conclusions: Recalled children's products were found to be available for sale online and were sold most of the time, presenting a risk of injury to children. Although the CPSC is charged with notifying the public of recalled items, these results suggest that potentially hazardous products are recirculating online. A multi-front initiative to decrease the presence of hazards in online auctions is needed. This initiative should include increased manufacturer efforts to improve recall return rates, a requirement by online auction sites that sellers verify non-recall status before item posting, and parental checks of government recall websites before item purchase. Investigation of parental understanding and awareness of recalls and the potential risks associated with recall announcements is needed.
\end{abstract}

A ccording to the National Electronic Injury Surveillance System of the US Consumer Product Safety Commission (CPSC), an estimated 230000 annual visits to emergency departments in the United States are due to injuries associated with nursery products and toys. ${ }^{1}$ Poorly designed children's products have been associated with suffocation, entrapment, asphyxiation, burns, poisonings, falls, and lacerations. ${ }^{2}{ }^{3}$ From 1999 to 2001, 149 deaths associated with nursery products were reported for children age 5 and younger, and medical case studies have been described..$^{4-7}$ In many cases, injuries associated with poorly designed children's products are preventable. ${ }^{8}$

In the US, products that have either violated safety standards or present a significant risk of injury to the public are recalled and announced to the public via press releases by the CPSC. Since the Consumer Product Safety Act of 1972, over 1000 different child products and toys have been recalled and are currently described on the CPSC website (www.cpsc.gov). Recalls on children's products have been found to account for $43 \%$ of total recalls announced by the CPSC and account for over $50 \%$ of injuries due to recalled products reported. ${ }^{9}{ }^{10}$ In the last decade there have been 60 million units of child products recalled in the US. However, there are many unsafe products "at large", with only $16-18 \%$ return rates reported for all recalled products. ${ }^{11}$ Children's products may have particularly low return rates because they are lower cost items and often do not include product registration cards (CPSC recall effectiveness meetings, 2003). ${ }^{12-14}$

Previously recalled products have been found to be associated with a continuing number of child injuries, including cribrelated deaths. ${ }^{15}$ These and other recalled children's products that have not been returned to the manufacturer for destruction or repair have been found for sale in the secondhand marketplace. Upon examination of 301 thrift stores in the US,
$69 \%$ of stores were selling at least one hazardous product. ${ }^{16}$ With the recent advancement of technology and the popularity of online auction sites, such as eBay, recalled children's toys have the potential to be resold at high rates. Parents may find the competitive prices and ease of use as particularly attractive features of online auction sites. ${ }^{17}$ To date, the safety of children's products auctioned online has not been evaluated.

There has been concern noted by the CPSC regarding the potential for online auction sites to perpetuate the use of recalled products by consumers. ${ }^{18}$ The CPSC promoted a "Recall Double Check", suggesting that both buyers and sellers check the recall status of an item before listing or bidding. ${ }^{18}$ eBay has a policy prohibiting the sale of recalled products (www.pages.ebay.com/help/policies/recalled.html), with violations potentially resulting in cancellation of the listing, loss of account privileges, or account suspension. To date, there has been no formal evaluation of the effectiveness of these preventative measures in the literature. It is unclear if consumers of children's toys are utilizing existing methods of determining the recall status of these products, such as by consulting the CPSC website (www.cpsc.gov). The goal of this study is to provide an initial examination of recalled child-product sales on eBay and determine implications for prevention of injury from unsafe second-hand children's products.

\section{METHODS}

\section{Observation of an online auction site}

The most popular online auction site (eBay) was monitored for 30 consecutive days for the presence of 141 child and infant products (herein referred to as "target items") that had been previously recalled. All target items were abstracted from the CPSC website (www.cpsc.gov) and were featured in press releases dated from 1992 to 2004. An initial sample of 150 children's toys and products was randomly selected from 
recalled items that met the following criteria: there were at least 5000 recalled units or $<5000$ units and associated with a hazard that could eventuate in fatality; there was a detailed picture, drawing, or description of the items sufficient for identification purposes; and the items were intended for use with or by children and recalled because of risk of injury. Owing to the presumed difficulty in identifying recalled clothing, clothing items were excluded from the search. In addition, automotive-related items, such as child passenger safety seats, are outside the jurisdiction of the CPSC, and therefore were not included among target items. Nine of the original target products were excluded from the search because of insufficient detail provided in press releases for visual identification necessary for this type of online search. The resulting target items consisted of 20 different types of child products and toys (see Appendix A, available online at http://ip.bmj.com/supplemental).

The 141 target items were entered individually into the eBay "search" function using at least three different search terms moving from specific to more generic product identifiers, including manufacturer and product name, product name only, and more general product type. Active eBay auction listings were searched for each target item once every 7 days for 4 consecutive weeks. Only auction listings that included at least one photograph were observed in order to improve ability to identify potential "hits".

All potential "hits" on the recalled target items were crossmatched with the descriptions and photographs found in the CPSC press releases. Company websites and telephone numbers found in the recall press releases were consulted to better determine recall status. If any disconfirming information was found and the recall was not supported, the item was no longer tracked.

For all recalled children's products and toys found at the online auction site, item specifics (eg, product type) and consumer behavior (eg, number of bids, selling price) were documented. In addition, seller information available to the public in the auction listing was collected. This information included the date that the seller registered with eBay, the percentage of positive feedback received from fellow eBay members based on prior auction participation, and self-reported state and/or country of residency.

\section{RESULTS}

\section{Item characteristics}

During the search period, 190 web-based auctions contained a recalled or a probably recalled children's product. Of these auctions, 144 items $(76 \%)$ were matched via model number or product characteristics (eg, color, size, year of production), and an additional 46 items (24\%) were found to have a high probability of being a recalled item. For these high probability items, product description (eg, photograph) matched; however, it was impossible to confirm the date of item production. In most of these cases, the products were manufactured again after the recall with the same product characteristics (eg, color), making it difficult to determine if the product was indeed part of the recall. Forty five different recalled products of the initial 141 target items were found (see Appendix A).

Of the 190 recalled or probably recalled listings, $124(65 \%)$ of the auctions resulted in a sale of the item. Of the unsold items, $10(5 \%)$ were relisted during the observation period, and eight $(80 \%)$ relistings resulted in a sale. Thus, $69 \%(n=132)$ of the recalled items tracked during the search period were sold via online auction. A mean (SD) of 3.06 (2.08) independent bidders vied for each of the suspected recalled items, with each item receiving a mean of $6.76(6.78)$ bids. The median bid was US\$38.82 (€29.14, £19.68) (range US\$0.99-325.00; €0.74-244; £0.50-165).

Auction listings featured items from CPSC press releases dated 1992 and 1996-2004 and included some child products recalled because of documentation of child fatality $(n=12)$. Other reasons for recalls for the products found at the online auction included products that placed children at risk of asphyxiation $(n=75)$, electrical fire $(n=7)$, laceration, pinching, or bruising $(n=39)$, fall $(n=50)$, other hazard (eg, lead poisoning; $\mathrm{n}=1 \mathrm{l}$ ), or a combination of the above hazards $(\mathrm{n}=8)$. Several items were recalled as a preventative measure, and were not associated with any reported injuries or fatalities.

\section{Seller characteristics}

Demographic information provided by sellers in auction listings was reviewed. Over $90 \%$ of sellers, who listed a recalled or probably recalled item, were from 39 states in the US $(n=156)$ with Australia $(n=4)$, Canada $(n=4)$, Great Britain $(n=3)$, and Ireland $(\mathrm{n}=1)$ also represented. Twelve of the sellers of recalled or probably recalled products listed multiple recalled items in separate auction listings during the search period.

Sellers of recalled children's items had been registered with eBay for a mean (SD) of 32.9 (19.8) months, with a range of 180 months of eBay membership. Sellers had positive feedback ratings of $99.5(1.4) \%$, based on a median of 199 feedbacks (range 0-12 821) regarding each of the seller's previous sales or purchases. Table 1 lists item and seller characteristics for auctions featuring recalled items.

\section{DISCUSSION}

During the observation period, several children's products that had been recalled were present on eBay, despite its policy

\begin{tabular}{|c|c|c|c|}
\hline & Toys $(n=70)$ & Products $(n=120)$ & Total $(n=190)$ \\
\hline \multicolumn{4}{|l|}{ Item characteristics } \\
\hline Highest bid (US\$) & $23.90(34.20)$ & $45.50(52.00)$ & $38.83(48.10)$ \\
\hline Highest bid (US\$) & 13.50 & 31.28 & 21.50 \\
\hline Number of bidders & $2.4(1.8)$ & $3.3(2.2)$ & $3.0(2.1)$ \\
\hline Number of bids & $4.2(4.5)$ & $7.8(7.3)$ & $6.8(6.8)$ \\
\hline Sold (\%) & 58.6 & 69.2 & 65.3 \\
\hline Relisted (\%) & 9.7 & 18.9 & 15.2 \\
\hline Total sold (\%) & 61.4 & 74.2 & 69.5 \\
\hline \multicolumn{4}{|l|}{ Seller characteristics } \\
\hline Active (months) & $33.54(20.2)$ & $32.63(19.6)$ & $32.76(19.8)$ \\
\hline Positive feedback (\%) & $99.5(0.8)$ & $99.5(1.7)$ & $99.5(1.4)$ \\
\hline Feedback (mean number) & 570.5 & 100.0 & 199.0 \\
\hline Feedback range & $0-12821$ & $0-7969$ & $0-12821$ \\
\hline
\end{tabular}


against the sale of recalled products. These potentially dangerous products were resold over half of the time, placing other children at risk of injury. Although the present search consisted of less than $10 \%$ of all recalled children's items and was for a relatively short period of time, many questionable items surfaced during the online search period. Recalled or probably recalled items that were listed for sale were diverse in form and function, and included such items as bassinets, play yards, baby walkers, and safety devices, as listed in Appendix A. Almost one third of target recalled items were found, with many of these items having multiple listings. The potential injuries associated with the recalled toys found represented a wide spectrum of injury types and fatality, although it cannot be determined from this study what the level of risk was for the specific families who may have purchased these items for use with children. Several of the found items were from recalls released more than 5 years before the data collection period, demonstrating that children's products can recirculate many years after initial production.

\section{Seller characteristics}

Sellers of the recalled or probably recalled products were experienced and reputable dealers, as evidenced by the average length of time registered with eBay, feedback ratings from fellow eBay members, and the number of previous online auction interactions-that is, sales and purchases. The sellers had been members of the online auction site for an average of nearly 3 years and had participated, either as a seller or a buyer, in a median of nearly 200 auctions. Even sophisticated eBay users appear to be unaware and/or uncooperative of the policies to keep recalled products from being exchanged. Further, the positive ratings that fellow eBay members gave these sellers suggest that parents may trust the safety of the items, because a seller's reputation has been found to be a proxy for product quality characteristics. ${ }^{19}$

One noted advantage of web-based auctions is the elimination of geographical barriers. ${ }^{17}$ However, the wide dissemination of recalled products complicates this public health concern, because there are no international laws regarding the resale of recalled products or mechanisms by which to alert consumers of faulty products. The suspect child products found during the online search were located in 39 states of the US, as well as Great Britain, Australia, Ireland, and Canada. Sellers from outside of the US may not be aware of the mission of the CPSC or the US federal recall website, www.recalls.gov, or may be uncertain of policies regarding recalled products in their country.

\section{Parent knowledge of online recalls}

On average, three individuals bid on each product, presumably unaware of the potentially hazardous nature of the item. Although the recall status of some of the suspected products without the model number could not be confirmed, the bidders were at the same disadvantage. Thus, parents were actively bidding on a product that could not be ruled out as a hazardous product and may have assumed that the auction site policies regarding recalled items are routinely enforced.

The number of instances of recalled items being sold in their respective auctions is of concern. In the ideal study, these rates would be compared with sale rates for similar non-recalled products. However, the fact that multiple people bid on these items suggests a problem with consumer awareness of this health threat. This finding is consistent with previous research regarding the lack of parental awareness and worry about child injury in general. ${ }^{20} 21$ Further research is needed on the extent to which parents understand the dangers of recalled products and their actions to protect their children from this hazard. It is unclear whether those parents purchasing recalled items from the online auctions were unaware of the recall, or had an assumption of product safety.

\section{Study limitations}

Although the current online auction search was extensive, it was not exhaustive: the number of hazards found during the search period is likely to be a conservative estimate of the true number of recalled child products featured in online auctions. Firstly, the targeted recall items represented a small sample of more than 1000 recalled children's products and toys. Secondly, the large volume of children's items listed on eBay for sale on any given day made it impossible to search each auction listing individually. Auction listings of recalled items that used unusual phrases, misspelled words, or had inaccurate product descriptions would not have been captured by the search strategy used in this study. Auction listings that feature multiple products, such as lots of dolls, may not list individual items by name; therefore, recalled items within such listings would not have been identified. Thirdly, at the time of data collection, sellers on eBay could choose a 3, 5, 7 or 10 day listing. Recalled items featured in shorter auctions may have been missed, as well as those items that feature an option for early termination if the buyer chooses to pay a predetermined price for the item. It is likely that most of the listings were searched, however, given that the average length of eBay auctions is reported to be 6.6 days, approximately the same as the weekly observations of active listings used in this study. ${ }^{17}$

The lack of certainty regarding the recall status of some of the items is also of concern. It was difficult to determine with absolute certainty the recall status of some of the child products listed online. For items in the dataset, no disconfirming information was found, after checking of press releases, calling of hotlines, and checking of manufacturer websites. Although product and model numbers are the most definitive means of identifying a product that has been recalled, rarely do auction listings contain this information. Visual recognition was utilized to help determine recall status; however, manufacturers often reproduce a safer version of the same product after a recall without changing key identifiers (eg, colors, product name), making safe and unsafe products virtually indistinguishable. Arguably, this inability to distinguish recalled from newer, safer items may present a concern for non-child-related recalled products as well and should be addressed.

Another limitation of this study is the inability to determine how many recalled items were not listed, because sellers had used the mechanisms in place to check recall status and correctly refrained from selling the item. Similarly, the intentions of the bidders could not be measured by current

\section{Key points}

- A variety of previously recalled children's products were found for sale on the internet's most popular auction site.

- Mechanisms to prevent the resale of unsafe children's products via online auctions appear to be largely unsuccessful, with recalled items resold most of the time.

- Several of the products observed for sale were recalled more than 5 years ago, thus increased manufacturer efforts to decrease the shelf-life of recalled children's products are needed.

- Auction sites should require additional product information that would aid in the identification and removal of unsafe children's products and toys. 
methodology. Some bidders may have been attempting to acquire products for alternative reasons (eg, collectables), and may not have intended to use the items with children. Nevertheless, the lack of discretion by the sellers and potential buyers we did observe suggests that current measures to protect children from online hazards are in need of improvement.

\section{Implications for prevention}

To address the concerns documented by this study, online auction sites should require more information about a product before posting. For example, sellers should be required to check that the products they propose to auction have not been recalled by the CPSC and electronically sign a statement indicating that the items have not been previously recalled or have been repaired by the manufacturer. Sellers can use federal websites, www.recalls.gov or www.cpsc.gov, to check the recall status of their items. Auction listings should require the following product information: product and company name, model and/or serial number, where the product was purchased. The policies against the sale of recalled items should be enforced by internet auction sites, just as "bricks and mortar" vendors are required to remove such products from shelves. Enforcement of this policy, as compared with enforcement of other policies (eg, prohibition of the sale of firearms) appears to be lacking. Direct links to product recall websites such as www.recalls.gov, the UK's www.recallnotice.co.uk, and Canada's www.hc-sc.gc.ca should be featured prominently at the bottom of each auction listing. Further, a centralized database of product recalls from various nations would assist consumers in making decisions regarding the safety of products sold in international auctions.

These recommendations address only a part of the larger public health concern of consumer product safety. The primary goal should be to decrease the number of units of recalled products "at large" via interventions to increase product returns for repair or replacement. By decreasing the average life of recalled children's products, faulty products will be less likely to be found for second-hand resale. In the US, manufacturers should be required to be more aggressive in retrieval of recalled products, and the CPSC should investigate alternative ways to advertise present and past recalls. ${ }^{22}$ Manufacturers should be required to change product names and/or color and design features after a recall to increase the likelihood that recalled products are identified more readily.

This study highlights the concerns for child safety as the internet has made the circulation of recalled products via online markets inexpensive, convenient, and expeditious. Even the most vigilant parents may have difficulty safely navigating the online marketplace because of the volume of recalls and the limited product information available. A broader examination of the role of the internet in the distribution of recalled children's products is needed, as is the computation of injury rates that may result from this health threat. Further, reasonable goals in reducing the risk of "recall recirculation" have yet to be established by the field. Efforts to decrease the presence and exchange of recalled products via parent awareness, manufacturer efforts, and changes in online auction procedures should be systematically examined.

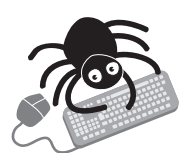

Appendix $A$ is available online at http://ip.bmi.com/ supplemental.

\section{Authors' affiliations}

Keri Brown Kirschman, Department of Psychology, University of Dayton, Dayton, Ohio, USA

Gary A Smith, Center for Injury Research and Policy, Columbus Children's Research Institute, Children's Hospital, Columbus, Ohio, USA, Ohio State University, College of Medicine and Public Health, Department of Pediatrics, Columbus, $\mathrm{OH}$, USA

Competing interests: None.

\section{REFERENCES}

1 US Consumer Product Safety Commission. US Consumer Product Safety Commission 2003. Annual Report to Congress. Washington DC: US Consumer Product Safety Commission, 2003.

2 Centers for Disease Control and Prevention. Toy-related injuries among children and teenagers, United States, 1996. Morb Mortal Wkly Rep 1997;46:1185-990.

3 US Consumer Product Safety Commission. Consumer product safety review, Vols. 1-10. Washington, DC: US Consumer Product Safety Commission, 19962005.

4 US Consumer Product Safety Commission. Nursery product-related injuries and deaths to children under age five. Washington, DC: US Consumer Product Safety Commission, 2004, http://www.cpsc.gov/library/foia/foia05/os/ toymemo03.pdf (accessed 12 Jun 2007).

5 VanArsdale JL, Leiker RD, Kohn M, et al. Lead poisoning from a toy necklace. Pediatrics 2004; 114:1096-9.

6 Nakamura SW, Pollack-Nelson C, Chidekel AS. Suction-type suffocation incidents in infants and toddlers. Pediatrics. 2003;111: e12-15, URL:http:// pediatrics.aappublications.org/cgi/content/full/111/1/e12l (accessed 12 Jun 2007).

7 Baker MD. Near-miss asphyxiation from a toy ball: a small parts failure. Pediatr Emerg Care 1989;5:34-6.

8 Felcher EM. Product recalls: gaping holes in the nation's product safety net. J Consum Aff 2003;37:170-9.

9 Kids In Danger. A minefield of danger: Children's product recalls in 2002 http://www.kidsindanger.org/publications/reports/2002_recallreport.pdf (accessed 12 Jun 2007).

10 News and Notes. Stronger safety system needed for product recalls. Inj Prev 2003;9:197.

11 Weintraub R. Child product safety: do current standards provide enough protection? October 6, 2004. Testimony to US House of Representatives Subcommittee on Commerce, Trade, and Consumer Protection. http:// www.consumerfed.org/pdfs/CPSCReauth061703.pdf (accessed 12 Jun 2007)

12 US Consumer Product Safety Commission. Summary of recall effectiveness meeting \#1. Motivating consumers to respond to recalls. Washington, DC: US Consumer Product Safety Commission, 2003, http://www.cpsc.gov/businfo/ rem_sum 1.pdf (accessed 12 Jun 2007).

13 US Consumer Product Safety Commission. Summary of recall effectiveness meeting \#2. New tools for recall effectiveness. Washington, DC: US Consumer Product Safety Commission, 2003, http://www.cpsc.gov/businfo/ rem_sum2.pdf (accessed 12 Jun 2007).

14 Consumer Product Safety Commission. Summary of recall effectiveness meeting \#3. Measuring recall effectiveness. Washington, DC: US Consumer Product Safety Commission, 2003, http://www.cpsc.gov/businfo/rem_sum3.pdf (accessed 12 Jun 2007).

15 Scheers NJ, Rutherford GW, Kemp JS. Where should infants sleep? A comparison of risk for suffocation of infants sleeping in cribs, adult beds, and other sleeping locations. Pediatrics 2003;112:883-9.

16 US Consumer Product Safety Commission. CPSC study of hazardous products in thrift stores. Washington, DC: US Consumer Product Safety Commission, 1999, http://www.cpsc.gov/library/thrift.html (accessed 12 Jun 2007).

17 Ariely D, Simonson I. Buying, bidding, playing, or competing? Value assessment and decision dynamics in online auctions. J Consum Psychol 2003;13:113-23.

18 US Consumer Product Safety Commission. Operation S.O.S. (Safe Online Shopping). Consumer Product Safety Review 2000;4:1-3.

19 Melnik JI, Alm J. Does a seller's ecommerce reputation matter? Evidence from eBay auctions. J Ind Econ 2002;50:337-49.

20 Peterson L, Farmer J, Kashani JH. Parental injury prevention endeavors: a function of health beliefs? Health Psychol 1990;9:177-91.

21 Morrongiello BA, Dayler, L. A community-based study of parents' knowledge, attitudes, and beliefs related to childhood injuries. Can J Public Health 1996:87:383-8.

22 Christoffel JD, Christoffel KK. The Consumer Product Safety Commission's opposition to consumer product safety: lessons for public health advocates. Am J Public Health 1989;79:336-9. 